\title{
FORMAÇÃo DOCENTE: O PERFIL DOS PROFESSORES DE CiÊnCIAS dos aNos finais do ENSINO FundaMENTAL
}

TEACHER TRAINING: THE PROFILE OF SCIENCE TEACHERS IN THE FINAL YEARS OF ELEMENTARY SCHOOL

DOI: $\underline{\text { 10.23926/RPD.2526-2149.2020.v5.n2.p1234-1255.id796 }}$

\author{
Andrea Ribeiro \\ Mestre em Educação em \\ Ciências (PPGEC/UESC) \\ Coordenadora Pedagógica \\ (SEDUC/BA) \\ andreaeadprof@gmail.com
}

\section{Luciana Sedano}

Doutora em Educação

(FEUSP)

Professora Titular

(DCIE/UESC)

$\underline{\text { luciana.sedano@gmail.com }}$
Resumo: Este artigo tem por objetivos analisar o perfil de um grupo de professores que lecionam Ciências nos anos finais do Ensino Fundamental em uma rede municipal da Bahia, classificando-o de acordo com os indicadores de adequação da formação docente e discutir indicativos de uma formação compatível pedagogicamente com a etapa de ensino em discussão. Em uma abordagem qualitativa, apresentam-se e discutem-se dados de uma pesquisa de mestrado sobre Desenvolvimento Profissional. A análise foi construída com base em cinco categorias de adequação da formação. Como resultados foram encontrados 53 dos 67 docentes pesquisados com formação diversa da adequada para a área na qual estão atuando e predominância de pedagogos entre os professores que lecionam Ciências nos anos finais do Ensino Fundamental.

Palavras-chave: Formação de professores. Desenvolvimento Profissional Docente. Ensino de Ciências.

\begin{abstract}
This article aims to analyze the profile of a group of teachers who teach Science in the final years of Elementary Education in a municipal network in Bahia, classifying it according to the indicators of adequacy of teacher training and to discuss indications of a pedagogically compatible training with the teaching stage under discussion. In a qualitative approach, data from a master's research on Professional Development are presented and discussed. The analysis was based on five categories of training adequacy. As a result, 53 of the 67 professors surveyed were found to have different training than the appropriate one for the area in which they are working and the predominance of pedagogues among teachers who teach Science in the final years of Elementary School. Keywords: Teacher Training. Teacher Professional Development. Elementary School. Science Teaching.
\end{abstract}




\section{INTRODUÇÃO}

A formação dos professores tem sido um tema recorrente nas pesquisas em educação, sobretudo, como forma de evidenciar seu papel para a melhoria da educação e como meio de buscar explicações e soluções para os problemas educacionais a partir de adequações na formação dos docentes.

Em se tratando do ensino de Ciências, existe, da mesma forma, uma grande preocupação com a formação dos professores, retratada também nas linhas de pesquisas dos Programas de Pós-graduação (PPG) Stricto Sensu, em especial os Multidisciplinares, que evidenciam algumas questões relacionadas à formação docente por apresentarem tópicos como política e formação de professores. Apesar da relevância do tema em questão, ainda nos deparamos com situações controversas em nossas redes municipais de ensino em relação à adequação da formação docente, atuação profissional e o perfil dos professores que atuam na disciplina Ciências nos anos finais do Ensino Fundamental.

E foi diante desse cenário e a partir de uma pesquisa realizada durante um mestrado em Educação em Ciências que trouxemos alguns dados para fomentar uma discussão pertinente sobre disparidades entre a formação dos professores e sua atuação profissional como causadoras de rompimentos e descontinuidades na formação docente e potenciais dificultadoras do Desenvolvimento Profissional Docente (DPD), bem como para os próprios objetivos de aprendizagem das Ciências.

A pesquisa foi realizada no contexto de uma rede municipal de educação do sul da Bahia, para a qual usaremos o nome fictício de $\mathrm{Crystal}^{1}$ no intuito de preservar a identidade dos participantes. Os dados foram obtidos com base nas informações sobre o Grupo de Orientação de Estudos e Prática (GOEP), uma proposta de Formação Continuada promovida pela Secretaria Municipal de Educação do referido município, durante o triênio de 2014 a 2016, aos professores efetivos que ministravam a disciplina Ciências da Natureza para alunos matriculados nos anos finais do Ensino Fundamental.

De acordo com o Relatório Técnico Semestral (janeiro a julho) do Departamento de Educação Básica do município pesquisado, as ações formativas tiveram início no ano de 2013

\footnotetext{
${ }^{1} \mathrm{Na}$ lista de referências relacionada ao documento Crystal (2013) não registraremos, excepcionalmente, o nome real do município (no local apropriado para a identificação da cidade de publicação) pelas razões de sigilo exigidas para a pesquisa, que foi submetida e aprovada pelo Comitê de Ética em Pesquisa com seres humanos.
} 
apenas com os professores da área de Expressão ${ }^{2}$. No entanto, esse mesmo documento apontava em uma das suas metas para o quadriênio 2013-2016: "assegurar a formação continuada e em contexto para os professores que atuam no Ensino Fundamental anos finais. ” (CRYSTAL, 2013, p. 53).

Os encontros do GOEP foram organizados anualmente, tendo como orientador de estudos um professor efetivo, licenciado em Química, da rede municipal com carga horária de 20h semanais, que correspondem a 4 horas diárias de trabalho, totalmente dedicadas ao trabalho da formação e acompanhamento das 12 escolas participantes.

Durante o tempo total de duração do GOEP, aconteceram 20 encontros formativos com carga horária total de $80 \mathrm{~h}$, tendo temáticas diversas voltadas para o ensino de Ciências, divididos da seguinte maneira: 5 encontros de 4h cada em 2014, totalizando 20h; 8 encontros de $4 \mathrm{~h}$ cada em 2015, totalizando 32h; 7 encontros de 4h cada em 2016, totalizando $28 \mathrm{~h}$.

A partir de um delineamento didático-histórico do programa de formação, pretendemos, com este artigo, analisar o perfil de um grupo de professores que lecionam Ciências nos anos finais do Ensino Fundamental em uma rede municipal da Bahia, classificando-o de acordo com os indicadores de adequação da formação docente e discutir indicativos de uma formação compatível pedagogicamente com a etapa de ensino em discussão.

Para conhecer o perfil desses professores, utilizamos como categorias para classificálos os indicadores de adequação da formação docente divulgados por meio da Nota Técnica número 020/2014 (INEP, 2014), e analisar indicativos de uma formação adequada legal e pedagogicamente com a etapa de ensino pesquisada.

\section{Perfil dos CURSistas}

O GOEP foi divulgado amplamente entre todos os professores de Ciências lotados em escolas municipais que lecionavam a disciplina Ciências e coordenadores pedagógicos. O convite foi direcionado a todas as escolas da rede municipal que contemplavam os anos finais do Ensino Fundamental; no entanto, apenas 6 professores e 1 coordenador pedagógico obtiveram a frequência considerada no limite da metade da carga horária de presença durante os 3 anos de duração do programa. Para este artigo, além desses professores, foram inseridas no grupo de entrevistados a assessora responsável pela organização da formação e sua

\footnotetext{
${ }^{2}$ Expressão era o termo utilizado para nomear a área de conhecimento que envolvia as disciplinas: Língua Portuguesa, Língua Estrangeira, Artes e Educação Física de acordo com a proposta vigente no Ciclo de Formação Humana do município em 2002 e permanece até os dias atuais.
} 
assistente, e excluída a coordenadora pedagógica por motivo também de infrequência em 2014, ficando organizado segundo o Quadro 1: 2 Assessoras do Ensino Fundamental; 1 Orientador de estudos e 4 professoras participantes, somando 7 entrevistados para esta pesquisa como demonstra o quadro.

O Quadro 1 conta também com dados sobre a formação inicial do participante, o ano de conclusão do curso e a carga horária de trabalho desse professor na rede municipal, sendo de extrema relevância considerar esses dados como forma de identificar quem são os docentes que ministram aulas de Ciências para os alunos dos anos finais do Ensino Fundamental.

Quadro 1 - Perfil dos sujeitos da pesquisa

\begin{tabular}{|c|c|c|c|c|c|c|}
\hline \multicolumn{7}{|c|}{ DADOS DOS PARTICIPANTES DA PESQUISA } \\
\hline \multirow{2}{*}{\multicolumn{2}{|c|}{ PROFESSOR }} & \multicolumn{2}{|c|}{ FREQUÊNCIA } & \multirow[t]{2}{*}{ FORMAÇÃO } & \multirow[t]{2}{*}{ ANO } & \multirow[t]{2}{*}{$\mathrm{CH}$} \\
\hline & & 2014 & $\%$ & & & \\
\hline & Luria $^{3}$ & 16 & 80 & Pedagogia & 1997 & $40 \mathrm{~h}$ \\
\hline 2. & Maria & 12 & 60 & Pedagogia & 2010 & $40 \mathrm{~h}$ \\
\hline 3. & Vânia & 20 & $100 \%$ & Letras & 2007 & $40 \mathrm{~h}$ \\
\hline 4. & Alena & 20 & $100 \%$ & Pedagogia & 2006 & $40 \mathrm{~h}$ \\
\hline \multicolumn{7}{|c|}{ ORIENTADOR DE ESTUDOS } \\
\hline 5. & João & \multicolumn{3}{|c|}{ QUÍMICA } & 1987 & $20 \mathrm{~h}$ \\
\hline \multicolumn{7}{|c|}{ ASSESSORIA TÉCNICO-PEDAGÓGICA DO ENSINO FUNDAMENTAL } \\
\hline & Telma & \multicolumn{5}{|c|}{ Assessora do Ensino Fundamental } \\
\hline 7 & Eva & \multicolumn{5}{|c|}{ Técnica do Ensino Fundamental } \\
\hline
\end{tabular}

Fonte: elaboração nossa a partir de dados da pesquisa.

Todas as entrevistadas são do sexo feminino e apenas o orientador de estudos é do sexo masculino, a faixa etária é de 35 a 65 anos, o tempo de serviço na rede municipal é de 9 a 25 anos. A frequência foi calculada com base no ano de 2014, somando-se a carga horária anual e calculando o percentual de frequência nas $20 \mathrm{~h}$ de encontros realizados durante o referido período, sendo que 2 professoras, Luria e Maria, obtiveram 80 e $60 \%$ respectivamente de frequência correspondente a 16h e 12h de encontros; as outras 2, Vânia e Alena, tiveram 100\% equivalente a $20 \mathrm{~h}$ de encontros.

Quanto à formação acadêmica inicial, é possível identificar que nenhuma das 4 professoras é licenciada na área de atuação, sendo 3 formadas em Pedagogia e 1 em Letras. O orientador de estudos possui Licenciatura em Química, o tempo de conclusão da graduação varia entre 9 e 31 anos. A carga horária de trabalho na rede municipal de ensino é de 40h semanais para todos os participantes, e de $20 \mathrm{~h}$ semanais para o orientador de estudos.

\footnotetext{
${ }^{3}$ Os nomes dos entrevistados são fictícios, preservando a identidade dos participantes do curso: proponentes e participantes.
} 


\section{FORMAÇÃO INICIAL X ATUAÇÃO PROFISSIONAL: ENTRE ADEQUAÇÕES E IMPROVISOS}

A formação inicial de professores para atuar no Ensino de Ciências da Natureza na Educação Básica está legalmente estruturada em três percursos formativos: a formação generalista, referindo-se à Licenciatura em Pedagogia, cujos egressos estão habilitados a atuar na Educação Infantil e anos iniciais do Ensino Fundamental; a formação especializada adquirida em cursos de Licenciatura Plena em Física, Química ou Ciências Biológicas, que habilitam para o ensino em turmas do $6^{\circ}$ ao $9^{\circ}$ ano que compõem os anos finais do Ensino Fundamental, além do Ensino Médio; e a formação integradora, que contempla a grande área das Ciências Naturais, base dos currículos das Licenciaturas em Ciências Naturais ou da Natureza (LCNs), que segundo Pereira-Ferreira e Meirelles (2017) é uma proposta que se apresenta de forma inovadora e tem como foco o diálogo entre as diferentes áreas do conhecimento, cujos egressos são habilitados para atuar na disciplina Ciências, prioritariamente, no Ensino Fundamental.

Essas trajetórias formativas estão delineadas de forma geral no Art. 62 da Lei de Diretrizes e Bases (BRASIL, 1996) que preconiza que nenhum professor deve atuar como docente sem que esteja habilitado em Licenciatura Plena e de forma específica, sendo que para cada Licenciatura existem diretrizes próprias (BRASIL, 2001; BRASIL, 2005), respectivamente de Ciências Biológicas, Física, Química e Pedagogia.

Entretanto, as pesquisas de Razuck e Rotta (2014) e de Gozzi e Rodrigues (2017) revelam que não existem diretrizes nacionais específicas para cursos de LCN. Tal situação pode ter caracterizado uma desvalorização do curso e, como consequência, ocasionado a alteração da nomenclatura e dos projetos de alguns cursos como forma de padronizá-los como Licenciatura em Ciências Biológicas, desconfigurando o caráter integrador das LCNs e passando a ser um curso voltado apenas para a Biologia, a exemplo do que recomenda o Parecer n. 190 (PARANÁ, 2010) sobre a renovação do curso de Ciências em uma Universidade do Paraná:

[...] que proceda a alteração de seu Projeto Pedagógico do Curso de Graduação em Ciências - Licenciatura, para Curso de Graduação em Ciências Biológicas Licenciatura, visto a inexistência de Diretrizes Curriculares Nacionais para o Curso, bem como o baixo número de alunos matriculados, conforme relato do Perito. (PARANÁ, 2010, p. 225)

De acordo com o parágrafo $4^{\circ}$ do Art. $3^{\circ}$, do Decreto n. 3.276 (BRASIL, 1999), "a formação de professores para a atuação em campos específicos do conhecimento far-se-á em cursos de licenciatura, podendo os habilitados atuar, no ensino da sua especialidade, em 
qualquer etapa da educação básica". No entanto, apesar de a legislação indicar a atuação dos graduados de acordo com a área de formação, segundo o Parecer CNE/CP n. o 009/2001:

Há ainda a necessidade de se discutir a formação de professores para algumas áreas de conhecimento desenvolvidas no ensino fundamental, como Ciências Naturais [...] que pressupõem uma abordagem equilibrada e articulada de diferentes disciplinas (Biologia, Física, Química, Astronomia, Geologia etc) [...] que, atualmente, são ministradas por professores preparados para ensinar apenas uma dessas disciplinas [...] A questão a ser enfrentada é a da definição de qual é a formação necessária para que os professores dessas áreas possam efetivar as propostas contidas nas diretrizes curriculares. (BRASIL, 2011, p. 1)

Em um panorama recente sobre o ensino de Ciências, a partir da obrigatoriedade da disciplina nas escolas (BRASIL, 1961) e a expansão para todo o Ensino Fundamental a partir da LDB n. 5.692 (BRASIL, 1971), Imbernon et al. (2011, p. 85) afirmam que “[...] o ensino de ciências no país é recente e apresenta resultados insuficientes, levando-nos a considerar que um dos problemas está no modelo de formação dos professores, que oscila entre a especificidade disciplinar e a generalidade". Tal afirmação nos faz pensar qual seria de fato, entre os percursos formativos atuais, aquele que atenderia melhor às necessidades formativas dos professores. Qual seria pedagogicamente, e não apenas legalmente, o mais indicado para formar professores de Ciências para os anos finais do Ensino Fundamental? Os cursos de LCN poderiam, então, substituir os modelos conteudistas e generalistas por um modelo de formação interdisciplinar, assim como propõe a própria organização curricular da disciplina Ciências, que envolve conhecimentos de Biologia, Física e Química?

Em relação à atuação profissional dos egressos das licenciaturas, o problema é ainda mais preocupante e não atende ao que determina a legislação, pois encontramos em todas as regiões do país docentes atuando em áreas ou disciplinas diferentes daquelas para as quais foram habilitados na sua formação inicial - licenciatura - e, em algumas não raras situações, existem bacharéis atuando na docência, descumprindo o Art. 62, da Lei n. 9.394 (BRASIL, 1996), que determina: “a formação de docentes para atuar na educação básica far-se-á em nível superior, em curso de licenciatura, de graduação plena, em universidades e institutos superiores de educação $[\ldots] "$.

Para Gatti (2014, p. 32), trata-se de um dos aspectos que se mostram recorrentemente revelados em estudos e pesquisas educacionais no que se refere à formação inicial: "professores improvisados em várias áreas do conhecimento por falta de licenciados na disciplina, ou licenciandos em curso". Nesse aspecto, temos questões sérias a serem discutidas em relação a essa inadequação entre formação inicial e atuação profissional, pois não estamos nesse momento avaliando a qualidade da formação oferecida aos professores e sim a ausência de 
formação adequada para ensinar Ciências no Ensino Fundamental, o que pode impactar direta e negativamente a aprendizagem dos alunos.

Neste artigo, nos debruçaremos sobre os dados na área de Educação em Ciências da Natureza obtidos a partir do perfil dos docentes que lecionaram Ciências nos anos finais do Ensino Fundamental, durante o triênio de 2014 a 2016 em uma rede municipal do sul da Bahia. Tais dados compõem a pesquisa de mestrado "Grupo de orientação de estudos e prática em ciências: análise sob a ótica do Desenvolvimento Profissional Docente" (RIBEIRO, 2019) cujo objetivo foi conhecer aspectos do Desenvolvimento Profissional Docente relevantes a partir da formação continuada ofertada a eles durante esse período. Aqui pretendemos inicialmente classificar a formação acadêmica dos professores de Ciências mediante as categorias utilizadas como indicadores de adequação da formação docente (INEP, 2014) a partir dos dados da pesquisa e dos dados do Censo Escolar (INEP, 2014) e, posteriormente, analisá-los com base nos indicadores que emergem das discussões de Gozzi e Rodrigues (2017) sobre o perfil formativo adequado para professores de Ciências do Ensino Fundamental.

Os dados apontados no Censo Escolar, quando analisados pelo INEP, são considerados como motivadores das políticas nacionais de formação da Coordenação de Aperfeiçoamento de Pessoal de Nível Superior (CAPES), a exemplo do Programa de Formação Inicial e Continuada para professores da Educação Básica (Profic) lançado em setembro de 2017, em substituição à antiga Plataforma Freire (Parfor).

O Profic apresenta na sua formatação em nível de graduação licenciaturas para profissionais em efetiva docência que possuem apenas bacharelado ou licenciatura diferente da sua área de atuação, em uma tentativa de melhorar a qualidade do ensino oferecido por eles e de cumprir as metas $15^{4}$ e $16^{5}$ do Plano Nacional de Educação (PNE 2014-2024), que tratam justamente de assegurar que "todos os professores e as professoras da educação básica possuam formação específica de nível superior, obtida em curso de licenciatura na área de conhecimento em que atuam" (OBSERVATÓRIO DO PNE, 2014).

\footnotetext{
4 "Meta 15: garantir, em regime de colaboração entre a União, os Estados, o Distrito Federal e os Municípios, no prazo de 1 (um) ano de vigência deste PNE, política nacional de formação dos profissionais da educação de que tratam os incisos I, II e III do caput do art. 61 da Lei no 9.394, de 20 de dezembro de 1996, assegurado que todos os professores e as professoras da educação básica possuam formação específica de nível superior, obtida em curso de licenciatura na área de conhecimento em que atuam".

5 "Meta 16: formar, em nível de pós-graduação, $50 \%$ (cinquenta por cento) dos professores da educação básica, até o último ano de vigência deste PNE, e garantir a todos(as) os(as) profissionais da educação básica formação continuada em sua área de atuação, considerando as necessidades, demandas e contextualizações dos sistemas de ensino".
} 
Possuir a formação inicial específica é parte importante dos saberes inerentes à prática docente. Sobre esses e os demais saberes inerentes, trataremos na seção seguinte da formação de professores voltada para o DPD, pois, a partir desse ponto, passamos a entender que existem elementos potencializadores que podem favorecer a aprendizagem contínua tão necessária ao desempenho dos professores.

\section{A Formação de professores sob a ótica do Desenvolvimento Profissional DOCENTE}

Para situar a perspectiva de formação mencionada anteriormente, utilizamos aqui a definição que melhor representa a concepção de Desenvolvimento Profissional Docente:

Aprendizagem profissional estruturada que resulta em mudanças nos conhecimentos e práticas do professor e melhoria na aprendizagem dos alunos, sendo, dessa forma, entendida como um desmembramento da Formação Continuada desde que esta seja organizada a partir de práticas formativas potencializadoras. (DARLINGHAMMOND; HYLER; GARDNER, 2017, p. 2, tradução nossa)

Além da definição de Darling-Hammond, Hyler e Gardner (2017), encontramos outras presentes na literatura que corroboram com a apresentada acima:

O desenvolvimento profissional consiste em todas as experiências naturais de aprendizado e aquelas atividades conscientes e planejadas que se destinam a beneficiar direta ou indiretamente o indivíduo, grupo ou escola e que contribuem, através delas, para a qualidade da educação em sala de aula. É o processo pelo qual, sozinhos e com os outros, os professores revisam, renovam e ampliam seu compromisso como agentes de mudança para os propósitos morais do ensino; e pelo qual eles adquirem e desenvolvem criticamente o conhecimento, habilidades e inteligência emocional essenciais para um bom pensamento profissional, planejamento e prática com crianças, jovens e colegas através de cada fase de suas vidas docentes. (DAY, 2002, p. 4, tradução nossa)

O desenvolvimento profissional docente caracteriza-se por uma atitude permanente de indagação, de formulação de perguntas e problemas e a busca de suas soluções. (MARCELO, 2009, p. 9).

Os programas de desenvolvimento profissional são esforços sistemáticos para promover a mudança nas práticas de sala de aula dos professores, nas suas atitudes e crenças e nos resultados de aprendizagem dos alunos. (GUSKEY; YOON 2009, p. $381)$.

As definições acima já dizem, por si mesmas, quais características devem ter as ações que objetivem promover o DPD e, para completar a informação, Darling-Hammond et al. (2009, p. 9-10, tradução nossa) destacam alguns requisitos básicos das práticas eficazes de desenvolvimento profissional:
a) ocorrem de modo intensivo e contínuo;
b) são conectadas às práticas docentes;
c) o foco de atenção incide sobre a aprendizagem dos alunos; 
d) são planejadas para atender aos conteúdos curriculares específicos;

e) são alinhadas às prioridades e às metas de melhoria do ensino e

f) são projetadas para construir relações fortes entre os professores.

Basta uma observação atenta a esses requisitos básicos citados acima para percebermos que não dizem respeito especificamente à formação continuada de professores, pois validam aspectos relacionados à organização do processo formativo e não a etapas definidas como inicial e continuada mesmo porque é justamente nesse ponto que a concepção do DPD diverge da maioria das propostas de formação que marcam pontualmente momentos que deveriam ser ininterruptos assim como o desenvolvimento das competências profissionais.

Definido como aprendizagem profissional estruturada, o DPD não se limita à formação continuada. Ao contrário disso, tem início antes mesmo da formação inicial, pois ainda na posição de aluno o futuro docente compartilha de crenças e concepções sobre o ensino e a aprendizagem, na própria concepção de carreira, cujas atitudes são inspiradas por elas tanto antes quanto após a formação inicial para a docência. Assim, a formação inicial é um fator determinante em relação à atuação do professor, pois desta depende a mobilização dos saberes inerentes a área para a qual está sendo habilitado enquanto docente, ainda que outros saberes como o conhecimento do currículo e a compreensão dos estudantes, tão importantes quanto os apropriados na graduação, sejam fortemente ancorados na prática de sala de aula.

\section{UM OLHAR PARA OS INDICADORES DE ADEQUAÇÃO DA FORMAÇÃO DOCENTE}

A qualidade do ensino da Educação Básica no Brasil e o seu processo de desenvolvimento são avaliados estatisticamente considerando não apenas o desempenho dos alunos, mas também o contexto econômico e social em que as escolas estão inseridas por meio de indicadores educacionais que colaboram no acompanhamento dos sistemas educacionais. Atualmente, 13 indicadores fazem parte da composição do Índice de Desenvolvimento da Educação Básica (IDEB) que monitora o processo de avaliação da aprendizagem dos estudantes, um deles é o indicador de adequação da formação do docente da educação básica que foi inserido ao processo em 2014 através da Nota Técnica n. 020/2014 (INEP, 2014) e tem a função de sintetizar a relação entre a formação inicial dos docentes de uma escola e as disciplinas que eles lecionam, considerando o ordenamento legal vigente.

Como parâmetro, o INEP (2014, p. 4) lançou uma tabela de referências com a formação considerada adequada para cada disciplina, "nesse sentido, como a forma comum de organização dos conteúdos curriculares está associada às disciplinas científicas, então, a 
docência pode ser qualificada a partir da relação entre a disciplina ministrada e a formação de quem a está lecionando".

Apresentaremos no Quadro 2 os cursos de formação consultados na Tabela 2 (INEP, 2014, p. 9-10) para a formação do docente apto a ministrar a disciplina Ciências, um dos campos específicos dos anos finais do Ensino Fundamental que deve acontecer nos diversos cursos de Licenciatura Plena para o ensino de sua especialidade.

Quadro 2 - Áreas de formação adequadas para o ensino de Ciências

\begin{tabular}{|c|c|}
\hline \multirow{4}{*}{} & Ciências Biológicas - Licenciatura \\
\cline { 2 - 3 } & Ciências Naturais - Licenciatura \\
\cline { 2 - 3 } & Física - Licenciatura \\
\cline { 2 - 3 } & Química - Licenciatura \\
\cline { 2 - 3 } & Química - Bacharelado com Complementação Pedagógica \\
\cline { 2 - 3 } & Física - Bacharelado com Complementação Pedagógica \\
\cline { 2 - 3 } & Ciências Biológicas - Bacharelado com Complementação Pedagógica \\
\cline { 2 - 3 } & Bacharelado Interdisciplinar em Ciência e Tecnologia com Complementação Pedagógica \\
\hline
\end{tabular}

Fonte: adaptação de INEP (2014, p. 9-10).

A partir dos cursos indicados como adequados no Quadro 2, podemos classificar a formação dos professores em efetivo exercício na docência de Ciências nos anos finais do Ensino Fundamental de acordo com o critério adequação, com base na sua formação acadêmica inicial ou complementar. Para isso, foram criadas e apresentadas na Nota Técnica n. ${ }^{\circ}$ 020/2014 (INEP, 2014) cinco categorias baseadas na LDB (BRASIL, 1996) e na Resolução CNE/CEB n. 4 (BRASIL, 2010) que retratam os perfis de regência das disciplinas encontrados nos dados do Censo Escolar para os anos finais do Ensino Fundamental e Ensino Médio.

O Quadro 3 demonstra as cinco categorias que servirão posteriormente para analisar os perfis dos sujeitos da pesquisa aqui apresentados.

Quadro 3 - Categorias de adequação da formação dos docentes em relação à disciplina que lecionam

\begin{tabular}{|c|l|}
\hline Grupo & \multicolumn{1}{c|}{ Perfil do docente } \\
\hline 1 & $\begin{array}{l}\text { Docentes com formação superior de licenciatura na mesma disciplina que lecionam, ou } \\
\text { bacharelado na mesma disciplina com curso de complementação pedagógica concluído. }\end{array}$ \\
\hline 2 & $\begin{array}{l}\text { Docentes com formação superior de bacharelado na disciplina correspondente, mas sem } \\
\text { licenciatura ou complementação pedagógica. }\end{array}$ \\
\hline 3 & $\begin{array}{l}\text { Docentes com licenciatura em área diferente daquela que lecionam, ou com bacharelado nas } \\
\text { disciplinas da base curricular comum e complementação pedagógica concluída em área } \\
\text { diferente daquela que lecionam. }\end{array}$ \\
\hline 4 & Docentes com outra formação superior não considerada nas categorias anteriores. \\
\hline 5 & Docentes que não possuem curso superior completo. \\
\hline
\end{tabular}
Fonte: INEP (2014, p. 5).

Para uma melhor compreensão sobre a adequação da formação docente, foi necessário dividir os perfis docentes em cinco categorias, como forma de tratar cada situação no sentido de favorecer a tomada de decisões pelos diferentes sistemas educacionais que se encontram 
desafiados a implementar ações formativas diversificadas para cada demanda apontada como prioritária.

O grupo 1 é composto por professores que têm formação adequada à disciplina que ensinam, não necessitando, portanto, de intervenção emergencial, e sim de políticas de formação continuada que possam facilitar o processo do seu desenvolvimento profissional docente. Do segundo grupo em diante, os docentes que o compõem estão em situação de inadequação da formação docente com sua atuação profissional, porém cada grupo trata de situações diferentes. No caso do grupo 2 , a formação em bacharelado está totalmente incoerente com a legislação vigente, que considera que apenas a licenciatura plena pode habilitar um profissional para a docência desde os níveis mais iniciais da Educação Básica.

No grupo 3, encontram-se os professores com a situação que mais nos chama atenção e que nos remete à discussão aqui iniciada, são docentes cuja formação, apesar de ser em licenciatura plena, não corresponde àquela que atua como docente. $O$ grupo 4 está composto por professores que possuem graduação, em área diferente da que lecionam e sem qualquer complementação pedagógica, por isso não foram classificados em nenhum dos grupos anteriores. $\mathrm{O}$ grupo 5 representa uma pequena parcela, que são aqueles que ainda não possuem formação em nível superior.

\subsection{OUTROS INDICADORES RUMO À FORMAÇÃO ADEQUADA}

Existem outros aspectos que indicam uma adequada formação para o ensino de Ciências que extrapolam as referências da legislação, são fruto de reflexões sobre qual o perfil mais adequado de docentes para lidar com as demandas da sociedade contemporânea, como o uso do conhecimento científico, apropriação das tecnologias educacionais e estratégias didáticas inovadoras e criativas, o que seria uma visão mais geral de um docente apto a atuar na Educação Básica, mesmo porque a legislação indica os caminhos.

De acordo com o Quadro 2, os cursos de Licenciatura em Ciências Biológicas, Ciências Naturais, Química e Física e os bacharelados nas referidas áreas com complementação pedagógica são considerados como adequados para habilitar o professor para a docência em Ciências nos anos finais do Ensino Fundamental, porém existem outras situações a serem discutidas sobre o que estamos chamando de adequação da formação docente e formação docente adequada.

Por outro lado, existe uma questão que tem uma maior ênfase nas pesquisas: a formação docente adequada para o ensino de Ciências, o que revela uma preocupação com a qualidade 
do ensino e não só com as estatísticas sobre quantidade de professores licenciados até 2024 para cumprir as metas do PNE (2014-2024).

De acordo com Pena (2017), políticas como o PNE traçam metas para acabar com a falta de professores sem formação específica nas escolas do país, porém não expressam uma preocupação e nem esforços para suprir as necessidades formativas dos docentes.

Para Gozzi e Rodrigues (2017), nas décadas de 1960 e 1970, a decisão de organizar os cursos de Licenciatura em Ciências implicava o aprofundamento epistemológico das diferentes áreas do conhecimento científico, conforme as diversas formações disciplinares de nível universitário em torno do movimento de "Ciência Integrada". Segundo os autores, de lá para cá foram poucas as proposições de cursos de formação de professores de Ciências para o Ensino Fundamental, visto que a maioria dos cursos implementados pelas universidades brasileiras está voltada para licenciaturas em áreas científicas específicas.

A partir de um levantamento feito com base em informações do e-MEC (BRASIL, 2017), sistema eletrônico de acompanhamento dos processos que regulam a educação superior no Brasil, foi possível encontrar no estado da Bahia apenas quatro cursos que abordam em suas propostas uma licenciatura efetivamente voltada para o ensino de Ciências nos anos finais do Ensino Fundamental, a escolha da localidade, pois, justifica-se por se tratar de uma pesquisa realizada no sul da Bahia. Os dados do levantamento estão organizados no Quadro 4.

Quadro 4 - Cursos de Licenciatura em Ciências Naturais na Bahia

\begin{tabular}{|c|c|c|c|c|}
\hline IES & $\begin{array}{l}\text { Universidade } \\
\text { Federal da } \\
\text { Bahia (UFBA) }\end{array}$ & $\begin{array}{c}\text { UNIVASF-BA } \\
\text { Campus } \\
\text { Senhor do Bomfim }\end{array}$ & $\begin{array}{l}\text { Universidade } \\
\text { Federal do } \\
\text { Recôncavo } \\
\text { da Bahia } \\
\text { (UFRB) }\end{array}$ & $\begin{array}{l}\text { Universidade } \\
\text { Federal do Sul da } \\
\text { Bahia (UFSB) }\end{array}$ \\
\hline $\begin{array}{l}\text { Dependência } \\
\text { administrativa }\end{array}$ & Federal & Federal & Federal & Federal \\
\hline Título do curso & $\begin{array}{l}\text { Licenciatura } \\
\text { em Ciências } \\
\text { Naturais }\end{array}$ & $\begin{array}{c}\text { Licenciatura em } \\
\text { Ciências da Natureza }\end{array}$ & $\begin{array}{l}\text { Licenciatura em } \\
\text { Ciências da } \\
\text { Natureza }\end{array}$ & $\begin{array}{c}\text { Licenciatura } \\
\text { Interdisciplinar em } \\
\text { Ciências da } \\
\text { Natureza e suas } \\
\text { Tecnologias }\end{array}$ \\
\hline Ano de criação & 1968 & 2009 & 2010 & 2014 \\
\hline $\begin{array}{c}\text { Habilitação para } \\
\text { docência }\end{array}$ & $\begin{array}{l}\text { Ciências, } \\
\text { Educação em } \\
\text { Saúde e } \\
\text { Educação } \\
\text { Ambiental }\end{array}$ & $\begin{array}{c}\text { O licenciado em } \\
\text { Ciências da Natureza } \\
\text { está habilitado para } \\
\text { atuação como } \\
\text { professor de Ensino } \\
\text { Fundamental }\end{array}$ & $\begin{array}{c}\text { Não existem } \\
\text { informações } \\
\text { disponibilizadas no } \\
\text { site da instituição }\end{array}$ & $\begin{array}{c}\text { Profissional } \\
\text { habilitado para o } \\
\text { ensino de Ciências } \\
\text { Naturais, nos anos } \\
\text { finais do Ensino } \\
\text { Fundamental, e de } \\
\text { Ciências da } \\
\text { Natureza, no Ensino } \\
\text { Médio }\end{array}$ \\
\hline
\end{tabular}




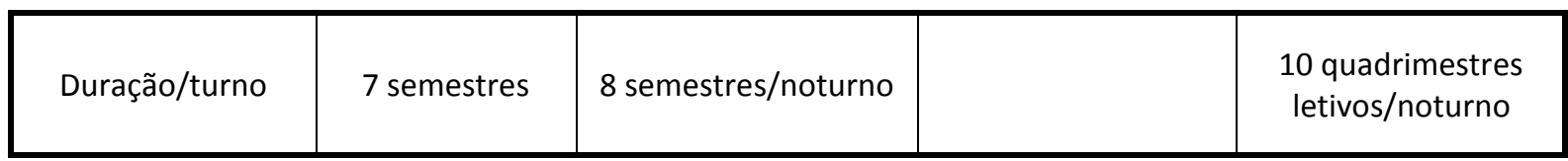

Fonte: elaboração nossa a partir dos dados do e-MEC (BRASIL, 2017).

A criação do primeiro curso se aproxima com a perspectiva da época em que a LDB de 1961 ampliou o ensino de Ciências, que era obrigatório apenas nas duas últimas séries do Ginásio, para todas as séries do curso Ginasial, atualmente denominado anos finais do Ensino Fundamental. Os cursos oferecidos no estado da Bahia variam em relação à nomenclatura, dois são denominados Licenciatura em Ciências da Natureza, um Ciências Naturais e um Licenciatura Interdisciplinar em Ciências da Natureza e suas Tecnologias. Todos eles estão vinculados à esfera federal e três deles duram no mínimo sete e no máximo oito semestres letivos, oferecidos na modalidade presencial. As cidades que sediam esses cursos são Salvador, Cruz das Almas, Senhor do Bomfim e Itabuna. Todos são Licenciaturas Plenas com foco no Ensino de Ciências no nível Fundamental.

Apesar da inexistência de uma diretriz curricular nacional para as LCNs, estas não foram totalmente substituídas por licenciaturas em áreas específicas, o que de fato aconteceu foi um entendimento errôneo de que para ensinar Ciências basta que o professor conheça conteúdos científicos específicos em profundidade e conhecimentos pedagógicos superficialmente para ser classificado nos critérios de adequação da formação docente. Porém de acordo com Carvalho e Gil-Pérez:

Nenhuma formação concebida como simples soma entre preparação científica e cursos gerais de educação, nem alguns estudos totalmente específicos constituem soluções corretas para proporcionar aos professores os conhecimentos exigidos para uma atividade docente eficaz. (CARVALHO; GIL-PÉREZ, 2011, p. 72).

Diante do exposto, inferimos que formação adequada para docência em Ciências nos anos finais do Ensino Fundamental sobrepõe a adequação da formação docente sugerida pelos documentos oficiais no que se refere a habilidades para ensinar, pois esta é uma tarefa complexa que exige do professor uma maior destreza. Portanto, ficamos diante de um impasse:

É necessário definir quem é o profissional adequado para lecionar $\mathrm{CN}$ nos anos finais do EF e qual formação específica esse profissional deve ter. As universidades precisam definir em qual seguimento esse profissional irá atuar. Os concursos públicos precisam contemplar em seus editais os profissionais diplomados na LCN. As políticas públicas precisam ser revisadas e aprimoradas, este estudo contribui no sentido de mostrar que é emergencial a situação da formação e do ensino de ciências no Brasil. É fundamental que os professores que lecionam $\mathrm{CN}$ nas escolas brasileiras tenham a formação específica exigida. (PENA, 2017, p. 78).

Tal contexto nos apresenta a necessidade de repensar, com base no caráter integrador da disciplina Ciências no nível básico, qual formação teria melhor impacto na aprendizagem dos 
docentes a ponto de torná-los aptos a ensinar Ciências Naturais de forma mais articulada com os conhecimentos e interdisciplinarmente com os conteúdos das diversas Ciências nos anos finais do Ensino Fundamental.

\section{Percurso MetOdológico: O PERFIL do PROFESSOR DE CiênCIAS}

Enquanto percurso metodológico, este trabalho é fruto de uma pesquisa de natureza qualitativa. De acordo com Flick (2009, p. 25) “[...] os métodos qualitativos consideram a comunicação do pesquisador em campo como parte explícita da produção de conhecimento, em vez de simplesmente encará-la como uma variável a interferir no processo". Tem o ambiente natural como fonte de dados, o foco no processo ao invés do produto, os dados são descritivos e a análise das pesquisas dessa natureza pretendem ocorrer dentro de um processo indutivo (LUDKE; ANDRÉ, 1986).

Com o objetivo de contextualizar nossos dados, buscamos informações no site do INEP, que é o órgão responsável por apresentar um painel educacional geral a partir dos dados coletados pelo Censo Escolar. Para esta pesquisa, utilizamos a seção da Educação Básica, selecionando o item Ideb com filtro por escola, estado, município e esfera administrativa e, por último, no setor organização, localizamos o indicador de adequação da formação docente para apresentar uma visão geral do município através das suas escolas.

Em seguida, buscamos informações mais específicas sobre a situação do município em relação à disciplina Ciências no site do Observatório do PNE, na meta 15, que diz respeito à formação inicial de professores, trazendo um panorama de cada disciplina separadamente em um dossiê por localidade.

Por fim, utilizamos o Sistema de Gestão Municipal para traçar o perfil dos professores que atuam nos anos finais do Ensino Fundamental com a disciplina Ciências, por meio do arquivo vínculo professor-turma, para identificar os professores que estavam lotados na disciplina Ciências do $6^{\circ}$ ao $9^{\circ}$ ano, independentemente de lecionarem concomitantemente outras disciplinas. Posteriormente, buscamos informações no banco de dados servidores, na aba formação, onde encontramos a formação acadêmica destes.

Após a coleta dessas informações, foi construída uma tabela com os 67 professores e sua formação docente inicial, sendo possível identificar o quanto o município apresenta de demanda para adequação da formação desses docentes com sua atuação profissional. 


\section{ANÁLISE DOS DADOS}

A rede pública municipal situada no sul da Bahia atualmente atende 4.047 alunos nos anos finais do Ensino Fundamental e conta com 208 professores lecionando as oito disciplinas que compõem a grade curricular. Os dados sobre as escolas estão registrados no Quadro 5 e representam o montante de professores que atuam nos anos finais do Ensino Fundamental, independentemente da disciplina que lecionam. São dados gerais da esfera administrativa municipal, envolvendo apenas as escolas urbanas que oferecem turmas do $6^{\circ}$ ao $9^{\circ}$ ano sem, no entanto, excluir aquelas unidades escolares que atendem também outros segmentos, sendo que o foco da pesquisa são os docentes que atendam aos anos finais do Ensino Fundamental.

A partir dos dados apresentados, foi possível identificar como o município pesquisado situa-se no cenário nacional em relação às categorias estabelecidas pelo INEP para considerar se a formação do professor atuante em sala de aula está adequada de acordo com seu perfil funcional.

Quadro 5 - Indicador de adequação da formação do docente, em porcentagem - anos finais do Ensino Fundamental por escola municipal urbana - Cidade Crystal

\begin{tabular}{|c|c|c|c|c|c|}
\cline { 2 - 6 } \multicolumn{1}{c|}{} & \multicolumn{3}{c}{ Categorias (quadro 3) utilizadas como indicadores de adequação da formação docente } \\
\hline ESCOLA & Grupo 1 & Grupo 2 & Grupo 3 & Grupo 4 & Grupo 5 \\
\hline E-1 & 23,2 & 5,6 & $\mathbf{3 5 , 4}$ & 30,3 & 5,5 \\
\hline E-2 & 22,2 & 0,0 & $\mathbf{7 7 , 8}$ & 0,0 & 0,0 \\
\hline E-3 & 24,2 & 0,0 & $\mathbf{4 6 , 8}$ & 0,0 & 29,0 \\
\hline E-4 & 14,0 & 0,0 & $\mathbf{5 7 , 0}$ & 0,0 & 29,0 \\
\hline E-5 & 23,4 & 6,5 & $\mathbf{6 5 , 4}$ & 4,7 & 0,0 \\
\hline E-6 & 17,2 & 3,1 & $\mathbf{5 7 , 3}$ & 22,4 & 0,0 \\
\hline E-7 & 26,3 & 6,8 & $\mathbf{6 1 , 0}$ & 5,9 & 0,0 \\
\hline E-8 & 4,9 & 0,0 & $\mathbf{9 5 , 1}$ & 0,0 & 0,0 \\
\hline E-9 & 19,9 & 0,0 & $\mathbf{5 7 , 0}$ & 16,6 & 6,5 \\
\hline E-10 & 18,2 & 10,6 & $\mathbf{5 1 , 0}$ & 16,7 & 3,5 \\
\hline E-11 & 18,1 & 12,5 & $\mathbf{6 6 , 7}$ & 2,7 & 0,0 \\
\hline Total das escolas & 19,4 & 4,7 & $\mathbf{5 6 , 9}$ & 13,2 & 5,8 \\
\hline municipais urbanas & & & & & \\
\hline
\end{tabular}

Fonte: elaboração a partir de dados da pesquisa e categorias utilizadas a partir de dados do INEP.

A primeira coluna do Quadro 5 apresenta as 11 escolas que oferecem turmas de anos finais do Ensino Fundamental, representadas por códigos do E1 ao E11, para preservar a identidade das unidades escolares, e estão organizadas na ordem em que aparecem no site do INEP. As escolas municipais rurais foram excluídas por contarem com classes multisseriadas e por serem diferenciadas na sua organização contando com um professor generalista para cada turma independentemente dos segmentos envolvidos. As colunas de 2 a 5 apresentam o 
percentual observado para cada grupo, de acordo com as escolas a partir dos dados do Censo 2016.

Menos de $20 \%$ dos docentes têm a formação ideal e adequada (grupo 1) para a disciplina que lecionam, enquanto que pouco mais de $80 \%$ dos docentes lecionam em disciplinas para as quais não estão habilitados (grupos 2, 3, 4 e 5). Isso significa que grande parte das disciplinas é lecionada por professores que, apesar de terem formação em nível superior, em maior número, estão atuando em áreas diversas da sua formação inicial.

Em relação à disciplina Ciências, essa situação não é diferente e pode ser observada nos dados disponíveis no Observatório do PNE referentes à proporção de docentes que possuem formação superior compatível com a área de conhecimento que lecionam nos anos finais do Ensino Fundamental. No ano de 2016, apesar de 96,1\% dos professores que ensinam Ciências possuírem nível superior, sendo 89,8\% em licenciatura, apenas 33,6\% deles apresentam compatibilidade entre a formação e a disciplina que lecionam.

Atendendo à proposta deste artigo, na sequência, são apresentados dados mais específicos coletados a partir dos professores que fazem parte do quadro docente efetivo e que lecionam a disciplina Ciências na rede municipal pesquisada. Esse levantamento preliminar foi realizado como forma de aproximar as pesquisadoras dos sujeitos da pesquisa, a fim de compreender algumas variáveis que facilitam ou dificultam o desenvolvimento profissional, já que a formação inicial marca uma etapa importante desse processo.

O Quadro 6 foi construído com base nas cinco categorias de adequação da formação dos docentes (INEP, 2014) em relação à disciplina que lecionam.

Quadro 6 - Classificação dos perfis docentes: adequação da formação docente

\begin{tabular}{|c|c|c|c|}
\hline $\begin{array}{c}\text { Categorias de } \\
\text { adequação da } \\
\text { formação dos } \\
\text { docentes em } \\
\text { relação à } \\
\text { disciplina que } \\
\text { lecionam } \\
\end{array}$ & TOTAL & ÁREAS DE FORMAÇÃO & QUANTIDADE \\
\hline \multirow{4}{*}{ GRUPO 1} & \multirow{4}{*}{14} & Ciências Biológicas - Licenciatura & 7 \\
\hline & & Ciências Naturais - Licenciatura & 4 \\
\hline & & Física - Licenciatura & 1 \\
\hline & & Química-Licenciatura & 2 \\
\hline GRUPO 2 & 0 & \multicolumn{2}{|c|}{$\begin{array}{c}\text { Bacharelado na disciplina correspondente, mas sem licenciatura ou } \\
\text { complementação pedagógica }\end{array}$} \\
\hline \multirow{2}{*}{ GRUPO 3} & \multirow{2}{*}{49} & Pedagogia - Licenciatura & 35 \\
\hline & & Letras - Licenciatura & 6 \\
\hline
\end{tabular}




\begin{tabular}{|c|c|c|c|}
\hline \multirow{2}{*}{} & & Matemática - Licenciatura & 4 \\
\cline { 3 - 4 } & & Filosofia - Licenciatura & 1 \\
\cline { 3 - 4 } & & História - Licenciatura & 1 \\
\cline { 3 - 4 } & \multirow{2}{*}{ GRUPO 4 } & Geografia - Licenciatura & \\
\hline & & & \\
GRUPO 5 & 3 & Bacharelado em Ciências Econômicas sem complementação pedagógica \\
& & \multicolumn{2}{|c|}{ Professores que não possuem formação em nível superior } \\
\hline
\end{tabular}

Fonte: elaboração a partir de dados da pesquisa.

Como já foram descritas anteriormente, dos cinco grupos apresentados, apenas o grupo 1 está definido como o que está com formação adequada para o ensino de Ciências, portanto os cursos constantes dessa categoria são aqueles que mais se aproximam da grande área das Ciências Naturais. Para facilitar a classificação dos professores, na coluna 3, áreas de formação, estão descritos os cursos dos quais os 14 professores do grupo 1 são egressos. Metade deles tem formação em Ciências Biológicas, o que caracteriza que essa licenciatura predomina na formação desse grupo de professores. Em um número menor, aparecem quatro professores licenciados em Ciências Naturais, um licenciado em Química e dois licenciados em Física. Apesar das especificidades de cada curso, segundo diretrizes próprias, todos habilitam professores para o ensino nos anos finais do Ensino Fundamental. De acordo com a classificação feita, não existiam nessa rede municipal bacharéis na área de Ciências Naturais ministrando aulas no momento da pesquisa, portanto o grupo 2 não foi contemplado.

Em relação ao grupo 3, podemos dizer que são os dados mais relevantes levantados nessa consulta, pois nesse grupo encontramos 49 dos 67 professores, dos quais 35 são pedagogos. A Licenciatura em Pedagogia habilita seu egresso para o ensino de todas as disciplinas, inclusive Ciências, apenas nos anos iniciais do Ensino Fundamental. De acordo com Devechi, Tauchen e Lanz (2017, p. 81):

\section{O curso de pedagogia parece ter ficado mais próximo das demais licenciaturas com foco na docência, com diferença de estar focado em mais de um objeto de ensino: docência na Educação Infantil e docência dos anos iniciais do Ensino Fundamental, sendo maior a carga horária para o conhecimento dos objetos de ensino.}

Ainda nesse grupo, encontramos 14 professores licenciados em áreas diversas, como Letras, Filosofia, História, Geografia e Matemática, o que torna ainda mais conflituosa a realidade local com as indicações legais sobre a formação docente.

Na sequência, temos o grupo 4 com 1 Bacharel em Ciências Econômicas ministrando aulas de Ciências, porém não foram encontradas informações sobre nenhum tipo de 
complementação pedagógica nos registros oficiais do sistema de gestão municipal. E, por fim, no grupo 5 estão enquadrados os professores que não possuem nível superior, o que corresponde a, aproximadamente, $4 \%$ do total, ou seja, três professores com formação em Magistério.

Diante do exposto, fica evidente a necessidade de uma reestruturação do quadro docente em questão, seja por meio de políticas de adequação da formação docente ou por contratação através de concurso público de professores habilitados a ministrar Ciências nos anos finais do Ensino Fundamental.

Temos situações distintas a serem avaliadas, uma delas seria a do grupo 1, que poderia ser contemplado com cursos de aperfeiçoamento através de formação continuada, e a situação do grupo 3, que, além de estar legalmente incompatível, está pedagogicamente desfavorável a aprendizagem dos alunos.

\section{CONSIDERAÇÕES FINAIS}

A aproximação inicial com os dados da pesquisa nos fez refletir sobre as influências do perfil dos professores pesquisados no seu processo de desenvolvimento profissional, o que nos levou a compreender como a legislação educacional e a literatura sobre a formação de professores abordam a temática em questão. Por isso, foram propostas, como objetivo para este artigo, a discussão sobre o perfil desses professores e a classificação da formação inicial deles a partir de indicadores de adequação da formação docente.

Como resposta aos questionamentos e inquietações iniciais, pudemos constatar que a problemática vivenciada em âmbito municipal é alarmante em relação ao contexto nacional, na qual professores vêm atuando de forma incompatível com sua formação inicial em um percentual de 33,6\%, enquanto que no município estudado esse percentual atinge 56,9\% dos docentes. Esse percentual revela a necessidade de que as políticas locais de formação docente sejam implementadas a partir de um levantamento minucioso das reais demandas, seguido do estabelecimento de parcerias com instituições de ensino superior que possam atendê-las.

Sem que seja possível concluir a discussão sobre o perfil real e o ideal dos professores que ensinam Ciências nos anos finais do Ensino Fundamental, consideramos extremamente relevante acompanhar por meio de pesquisas o processo de formação, bem como a sua atuação profissional, pois, dessa forma, provocaremos debates que envolvam a complexidade do ensino de Ciências no país.

Apesar de não terem sido avaliados diretamente, é provável que os alunos matriculados nos anos finais do Ensino Fundamental, cujos professores foram sujeitos da pesquisa que deu 
base aos dados deste artigo, não estejam recebendo um ensino satisfatório, visto que os professores que têm formação especializada não estão dando conta das problemáticas contextuais da sala de aula, e dificilmente os professores com formação generalista ou sem formação alguma conseguirão promover um ensino apropriado.

Embora o perfil traçado de grande parte dos sujeitos aqui citados não seja o idealizado para o ensino de Ciências nos anos finais do Ensino Fundamental, os professores envolvidos estão inseridos em um contexto nacional que precisa ser debatido cada vez mais. Precisaríamos de uma pesquisa um pouco mais abrangente envolvendo os docentes para entender quais circunstâncias os colocam em tal situação de total incompatibilidade entre sua formação e a área que atuam. Possivelmente, ao final da pesquisa, será possível revelar quais são as razões que potencialmente seriam favoráveis ao seu desenvolvimento profissional.

Ademais é possível afirmar que o Desenvolvimento Profissional Docente está interligado ao processo formativo do docente de forma que o transforma em um ciclo de aprendizagens contínuas e subsequentes onde a atuação profissional juntamente com as experiências formativas mobilizam saberes que advêm especialmente da prática, portanto, a coerência entre formação inicial, atuação profissional e formação continuada em serviço coaduna para a aprendizagem docente e consequente desenvolvimento profissional.

\section{REFERÊNCIAS}

BRASIL. Lei n. 4.024, de 20 de dezembro de 1961. Fixa as Diretrizes e Bases da Educação Nacional. Diário Oficial da União. Brasília, DF. 1961. Disponível em:

http://www.planalto.gov.br/ccivil_03/LEIS/L4024.htm. Acesso em: 13 fev. 2020.

BRASIL. Lei n. 5.692, de 11 de agosto de 1971. Fixa Diretrizes e Bases para o ensino de $1^{\circ}$ e $2^{\circ}$ graus, e dá outras providências. Brasília, DF. 1971. Disponível em: https://www2.camara.leg.br/legin/fed/lei/1970-1979/lei-5692-11-agosto-1971-357752publicacaooriginal-1-pl.html. Acesso em: 14 fev. 2020.

BRASIL. Lei n. 9.394, de 20 de dezembro de 1996. Estabelece as Diretrizes e Bases da Educação Nacional. Brasília, DF. 1996. Disponível em:

http://www.planalto.gov.br/ccivil_03/leis/19394.htm. Acesso em: $17 \mathrm{fev} .2020$.

BRASIL. Decreto n. 3.276, de 6 de dezembro de 1999. Dispõe sobre a formação em nível superior de professores para atuar na educação básica e dá outras providências. Brasília, DF. 1999. Disponível em: http://www.planalto.gov.br/ccivil_03/decreto/D3276.htm. Acesso em: 2 mar. 2020.

BRASIL. Parecer CNE/CP n. ${ }^{\circ}$ 009/2001. Diretrizes Curriculares Nacionais para a Formação de Professores da Educação Básica, em nível superior, curso de licenciatura, de graduação plena. Brasília, DF. 2001. Disponível em: http://portal.mec.gov.br/cne/arquivos/pdf/009.pdf. Acesso em: $21 \mathrm{fev} .2020$. 
BRASIL. Parecer CNE/CES 1301/2001, de 6 de novembro de 2001. Ministério da Educação, Conselho Nacional de Educação. Estabelece as Diretrizes Curriculares Nacionais para os cursos de Bacharelado e de Licenciatura em Ciências Biológicas. Brasília, DF. 2001, Seção 1, p. 25, 2001. Disponível em: http://portal.mec.gov.br/cne/arquivos/pdf/CES1301.pdf. Acesso em: $13 \mathrm{fev} .2020$.

BRASIL. Parecer CNE/CES 1.303, 06 de novembro de 2001. Ministério da Educação, Conselho Nacional de Educação. Estabelece as Diretrizes Curriculares Nacionais para os cursos de Bacharelado e de Licenciatura em Química. Brasília, DF. 2001, Seção 1, p. 25. Disponível em: http://portal.mec.gov.br/cne/arquivos/pdf/CES1303.pdf. Acesso em: 13 fev. $\underline{2020 .}$

BRASIL. Parecer CNE/CES 1.304, 06 de novembro de 2001. Ministério da Educação, Conselho Nacional de Educação. Estabelece as Diretrizes Curriculares Nacionais para os cursos de Bacharelado e de Licenciatura em Física. Brasília, DF. 2001, Seção 1, p. 25. Disponível em: http://portal.mec.gov.br/cne/arquivos/pdf/CES1304.pdf. Acesso em: 13 fev. 2020.

BRASIL. Parecer 05/2005, de 13 de dezembro de 2005. Conselho Federal de Educação. Conselho Pleno. Estabelece Diretrizes Curriculares Nacionais para o Curso de Pedagogia. Brasília, DF. 2005. Disponível em: http://portal.mec.gov.br/cne/arquivos/pdf/pcp05_05.pdf. Acesso em: $13 \mathrm{fev} .2020$.

BRASIL. Resolução n. ${ }^{\circ}$ 4, de 13 de julho de 2010. Define Diretrizes Curriculares Nacionais Gerais para a Educação Básica. Brasília, DF. 2010. Disponível em: http://portal.mec.gov.br/dmdocuments/rceb004_10.pdf. Acesso em: 5 fev. 2020.

BRASIL. Instituições de educação superior e cursos cadastrados. 2017. Disponível em: http://emec.mec.gov.br/emec/nova. Acesso em: 12 mar. 2020.

CARVALHO, Anna Maria Pessoa; GIL-PÉREZ, Daniel. Formação de professores de ciências: tendências e inovações. 10. ed. Revisão técnica de Ana Maria Pessoa de Carvalho. São Paulo: Cortez, 2011.

CRYSTAL, Relatório Técnico Semestral (janeiro a julho). Departamento de Educação Básica. Secretaria Municipal de Educação. Município de Crystal. 2013

DARLING-HAMMOND, Linda; WEI, Ruth Chung; ANDREE, Alethea; RICHARDSON, Nikole.; ORPHANOS, Stelion. Professional learning in the learning profession. Washington, DC: National Staff Development Council, 12. 2009.

DARLING-HAMMOND, Linda; HYLER, Maria; GARDNER, Madelyn. Effective Teacher Professional Development. Learning Policy Institute, Palo Alto, CA, 2017.

DAY, Christopher. Developing teachers: The challenges of lifelong learning. Routledge. 2002. Disponível em: https://eric.ed.gov/?id=ED434878. Acesso em: 16 abr. 2020.

DEVECHI, Catia Piccolo Viero; TAUCHEN, Gionara; LANZ, Helza Ricarte. Educação comparada internacional: percepções sobre a formação de professores no Brasil e na 
Alemanha. Revista Espaço Pedagógico, Passo Fundo, v. 24, n. 1, 74-97, 2017. Disponível em: http://dx.doi.org/10.5335/rep.v24i1.6994. Acesso em: 23 jul. 2020.

FLICK, U. Introdução à pesquisa qualitativa. Tradução Joice Elias Costa. $3^{\mathrm{a}}$ ed. Porto Alegre: Artmed, 2009.

GATTI, Bernardete. Formação inicial de professores para a educação básica: Pesquisas e políticas educacionais. Est. Aval. Educ., São Paulo, v. 25, n. 57, p. 24-54, 2014. Disponível em: http://dx.doi.org/10.18222/eae255720142823. Acesso em: 23 jul. 2020.

GOZZI, Maria Estela; RODRIGUES, Maria Aparecida. Características da formação de professores de ciências naturais. Revista Brasileira de Pesquisa em Educação em Ciências, Belo Horizonte, v. 17, n. 2, p. 423-449, 2017. Disponível em: https://doi.org/10.28976/19842686rbpec2017172423. Acesso em: 14 maio 2020.

GUSKEY, Thomas; YOON, Kwang Suk. What Works in Professional Development? Phi Delta Kappan, Washington, v. 90, n. 7, p. 495-500, mar. 2009. SAGE Publications. 2009. Disponível em: http://dx.doi.org/10.1177/003172170909000709. Acesso em: 12 jan. 2020.

IMBERNON, Rosely Aparecida Liguori; GUIMARÃES, Eliane Mendes; GALVÃO, Rozana de Medeiros Souza; LIMA, Aldeniza Cardoso de; SANTIAGO, Lucídia Fonseca;

JANNUZZI, Célia Maria Lira. Um panorama dos cursos de licenciatura em ciências naturais (LCN) no Brasil a partir do $2^{\circ}$ Seminário Brasileiro de Integração de Cursos de LCN/2010. Experiências em Ensino de Ciências, Cuiabá, v. 6, n. 1, p. 85-93, 2011. Disponível em: http://if.ufmt.br/eenci/artigos/Artigo_ID134/v6_n1_a2011.pdf. Acesso em: 12 jan. 2020.

INEP. Instituto Nacional de Estudos e Pesquisas Educacionais Anísio Teixeira. Nota Técnica n. 020/2014: Indicador de adequação da formação do docente da educação básica. Brasília, DF: INEP, 2014.

INEP. Instituto Nacional de Estudos e Pesquisas Educacionais Anísio Teixeira. Censo Escolar Brasil. 2015. Disponível em: http://inep.gov.br/censo-escolar. Acesso em: 17 jun. 2020.

LÜDKE, Menga.; ANDRÉ, Marli. Pesquisa em educação: abordagens qualitativas. São Paulo: EPU, 1986.

MARCELO, Carlos. Desenvolvimento profissional docente: passado e futuro. Sísifo Revista de ciências da educação, Portugal, v. 8, p. 7-22. jan./abr. 2009. Disponível em:

http://www.unitau.br/files/arquivos/category_1/MARCELO_Desenvolvimento_Profissiona 1_Docente_passado_e futuro_1386180263.pdf. Acesso em: 27 mar. 2020.

OBSERVATÓRIO DO PNE. Proporção de docentes que possuem formação superior compatível com a área de conhecimento que lecionam: anos finais do Ensino Fundamental. 2014. Disponível em: http://www.observatoriodopne.org.br/metas-pne. Acesso em: 27 mar. 2020.

OCDE. Brasil no PISA 2015: análises e reflexões sobre o desempenho dos estudantes brasileiros. São Paulo: Fundação Santillana, 2016. 
PARANÁ. Conselho Estadual de Educação (CEE). Parecer CEE/CES no 190/10. Processo n. 1157/10: Renovação do Reconhecimento do Curso de Graduação em Ciências Licenciatura - Campus de Goioerê, PR. 2010. Disponível em:

http://www.cee.pr.gov.br/arquivos/File/pdf/Pareceres2010/CES/pa_ces_190_10.pdf. Acesso em: 12 mar. 2020.

PENA, Samira Cristina de Santana. Estudo quantitativo da carência e da formação de professores de ciências naturais para ensino fundamental. 2017. 89 f. Dissertação (PósGraduação em Ensino de Ciências e Matemática) - Universidade Federal de Sergipe, São Cristóvão, SE, 2017.

PEREIRA-FERREIRA, Cristiane.; MEIRELLES, Rosane Moreira Silva. O ensino de ciências nas diretrizes curriculares nacionais para a formação de professores da educação básica no Brasil: Um estudo preliminar. Anais do VIII Encontro Nacional de Pesquisa em Educação em Ciências - VIII ENPEC. Campinas: São Paulo, 2017. p. 1-13

RAZUCK, Renata Cardoso de Sá Ribeiro; ROTTA, Jeane Cristina Gomes. O curso de licenciatura em ciências naturais e a organização de seus estágios supervisionados. Ciência \& Educação, Bauru, v. 20, n. 3, p. 739-750, 2014. Disponível em:

http://dx.doi.org/10.1590/1516-73132014000300014. Acesso em: 4 abr. 2020.

RIBEIRO, A. Grupo de orientação de estudos e prática em ciências: análise sob a ótica do Desenvolvimento Profissional Docente. Dissertação de Mestrado., Universidade Estadual de Santa Cruz, UESC, Brasil. 2019.

Recebido em: 30 de junho de 2020.

Aprovado em: 30 de agosto de 2020. 